\title{
Identification of a novel de novo mutation in the NIPBL gene in an Iranian patient with Cornelia de Lange syndrome: A case report
}

\author{
Hamid Galehdari ${ }^{*}$, Roya Monajemzadeh², Habibolah Nazem², Gholamreza Mohamadian ${ }^{3}$ and \\ Mohammad Pedram ${ }^{4}$
}

\begin{abstract}
Background: Cornelia de Lange syndrome is characterized by dysmorphic facial features, hirsutism, severe growth and developmental delay. Germline mutations in the NIPBL gene with an autosomal dominant pattern and in the SMC1A gene with an X-linked pattern have been identified in Cornelia de Lange syndrome.

Case presentation: A two-month-old Iranian boy who showed multiple congenital anomalies was referred to the genetic center of a welfare organization in southwest Iran. He was the second child of a non-consanguineous marriage, born after full term with normal delivery. His birth weight was $3110 \mathrm{~g}$, his length was $46 \mathrm{~cm}$ and his head circumference was $30 \mathrm{~cm}$. Both parents were clinically asymptomatic, with no positive history of any deformity in their respective families.

Conclusions: Sequencing of the NIPBL gene from our patient revealed a single-base deletion of thymidine in exon 10 (c.516delT). This mutation presumably results in premature termination at codon 526. We did not observe this mutation in the parents of our patient with Cornelia de Lange syndrome. The results presented here enlarge the spectrum of NIPBL gene mutations associated with Cornelia de Lange syndrome by identifying a novel de novo mutation in an Iranian patient with Cornelia de Lange syndrome and further support the hypothesis that NIPBL mutations are disease-causing mutations leading to Cornelia de Lange syndrome.
\end{abstract}

\section{Introduction}

Cornelia de Lange syndrome (CdLS; http://www.ncbi. nlm.nih.gov/omim/122470), also known as Brachmannde Lange syndrome, is a clinically and genetically heterogeneous developmental disorder characterized by growth and mental retardation $[1,2]$. The prevalence of mild and classic CdLS is estimated to be as high as 1.6 to $2.2 / 100,000$ births [3]. Growth retardation is an almost universal finding in patients with CdLS and typically has a pre-natal onset. Mental retardation in patients with CdLS is often severe, resulting in a mean IQ of 53 [1]. Many patients also demonstrate autismlike behavior and self-injurious behavior [4]. No genderbased predilection has been reported, and no differences linked to maternal age or race has been described [3].

\footnotetext{
* Correspondence: galehdari187@yahoo.com

'Genetics Department, Shahid Chamran University, Ahwaz, Iran

Full list of author information is available at the end of the article
}

The majority of cases are sporadic, and very few familial cases of CdLS have been reported [4]. Pedigree analyses of several families have demonstrated autosomal dominant inheritance with both maternal and paternal transmission [5].

Multiple genes are considered to be responsible for CdLS, all of which are implicated in sister chromatid cohesion [6]. Mutations in the NIPBL gene on chromosome 5 p13.1 account for approximately $50 \%$ of CdLS cases and have been shown to cause both mild and severe forms of the disease [1]. The NIPBL gene is 9.5 $\mathrm{kbp}$ in length and contains 47 exons that encode two isoforms of 2804 and 2697 amino acids, termed delangin-A and delangin-B, respectively [1]. The human NIPBL proteins share homology with Drosophila melanogaster Nipped-B and Scc2 from the budding yeast Saccharomyces cerevisiae [6]. The NIPBL protein is directly associated with chromatin while playing a role in the loading of the cohesin complex that mediates

\section{C)

(C) 2011 Galehdari et al; licensee BioMed Central Ltd. This is an Open Access article distributed under the terms of the Creative Commons Attribution License (http://creativecommons.org/licenses/by/2.0), which permits unrestricted use, distribution, and reproduction in any medium, provided the original work is properly cited. 
sister chromatid cohesion to chromosomes. It also has a dose-dependent gene-regulatory function [7]. Furthermore, mutations in the SMC1A gene cause an X-linked form of CdLS [8]. Mutations in the SMC3 gene on chromosome 10 have also been reported to cause CdLS [9]. The SMC1A and SMC3 genes encode the two mitotic cohesion subunits [10]. Cohesin plays a role in sister chromatid cohesion during mitosis and meiosis, in DNA repair and in gene expression [11]. Evidence that cohesin regulates gene expression is accumulating rapidly [12-14] and supports the hypothesis that developmental deficits in patients with CdLS likely arise from changes in cohesin-regulated gene expression that alter transcription in multiple ways $[15,16]$. Here, we report the first molecular analysis of the NIPBL gene in an Iranian newborn baby diagnosed with CdLS.

\section{Case presentation}

A two-month-old Iranian boy with multiple congenital anomalies was referred to the genetic center of a welfare organization in Ahwaz (southwestern Iran).

\section{Medical history}

At birth, our patient exhibited arch-like confluent (synophrys) eyebrows; long, curly eyelashes; low anterior and posterior hairlines; long philtrum; anteverted nares; depressed nasal bridge; downturned corners of the mouth and thin lips; a high-arched palate; micrognathia; and low-set ears. He also had microcephaly; small hands, with the right hand missing one digit and the left hand having fused digits; hypertonicity; excessive body hair (hirsutism) on the back and feet; cryptorchidism; a small penis; and a low-pitched cry (Figure 1). Echocardiography revealed both an atrial septal defect and a ventricular septal defect in the newborn. Results of kidney sonography were normal. A computed tomography (CT) scan of the brain showed subarachnoid hemorrhage $(\mathrm{SAH})$ and intra-ventricular hemorrhage (IVH) with no sign of hydrocephalus.

\section{Family history}

Our patient was the second child of a non-consanguineous marriage, born after full term by normal delivery, with a birth weight of $3110 \mathrm{~g}$, length of $46 \mathrm{~cm}$ and head circumference of $30 \mathrm{~cm}$. Both parents were clinically asymptomatic, with no positive history of any deformity in their respective families.

\section{Discussion}

Three family members (our patient and his parents) were included in this study after informed consent was obtained. Genomic DNA was extracted using a standard protocol, and 46 coding exons (from exons 2 to 47 ) of the NIPBL gene were amplified by polymerase chain reaction assay as described previously [2]. Direct sequencing of the coding exons along with the flanking intron regions of the NIPBL gene was performed using the Big Dye Terminator Cycle Sequencing Ready Reaction Kit (Applied Biosystems; Darmstadt, Germany) on an ABI Prism 3700 automated genetic analyzer (Applied Biosystems).

Direct sequencing analysis of the proband demonstrated a heterozygous, single-nucleotide deletion (c.516delT) in exon 10 of the NIPBL gene, which resulted in a frame shift, leading to premature termination at codon 526 (Figure 2). Because of the absence of this mutation in the parents of our patient, we report here a novel de novo mutation of the NIPBL gene. To support the pathogenic nature of this mutation, we searched the genomes of 45 healthy individuals for similar mutations the NIPBL gene, with negative results.

\section{Conclusions}

The clinical features of CdLS vary widely among patients, ranging from the classic form, which is severe, to mild forms and including some individuals who have non-syndromic phenotypes but some form of mental retardation [17]. In spite of the differences in severity, the facial dysmorphisms have provided the most helpful

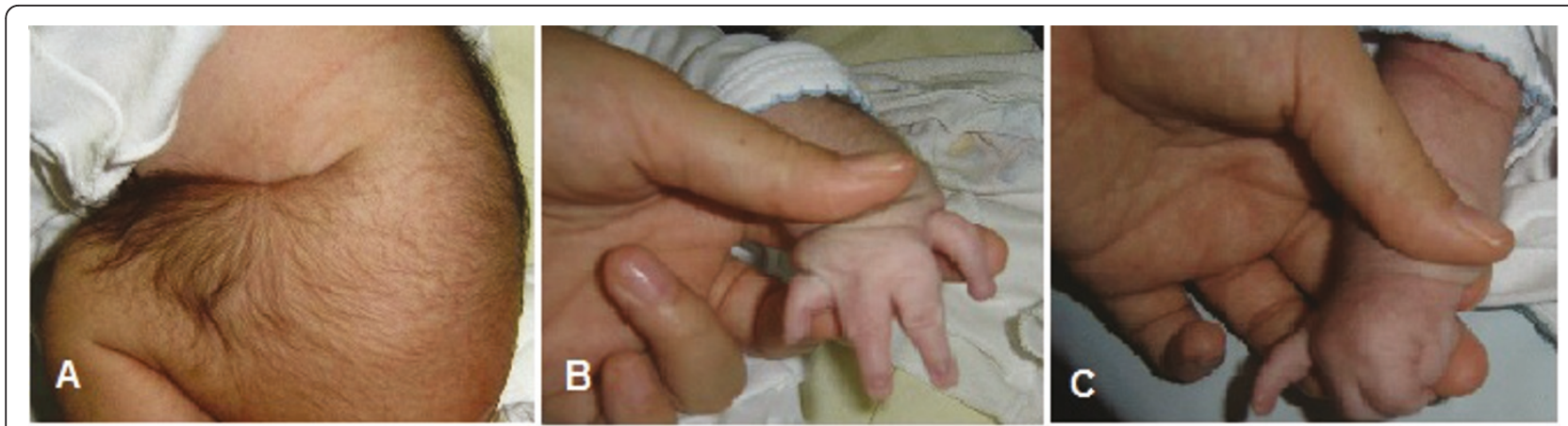

Figure 1 Characteristic features of Cornelia de Lange syndrome. (A) Hirsutism. (B,C) Variability of upper-limb abnormalities (distal reduction defect with missing and fused digits in the same child). 

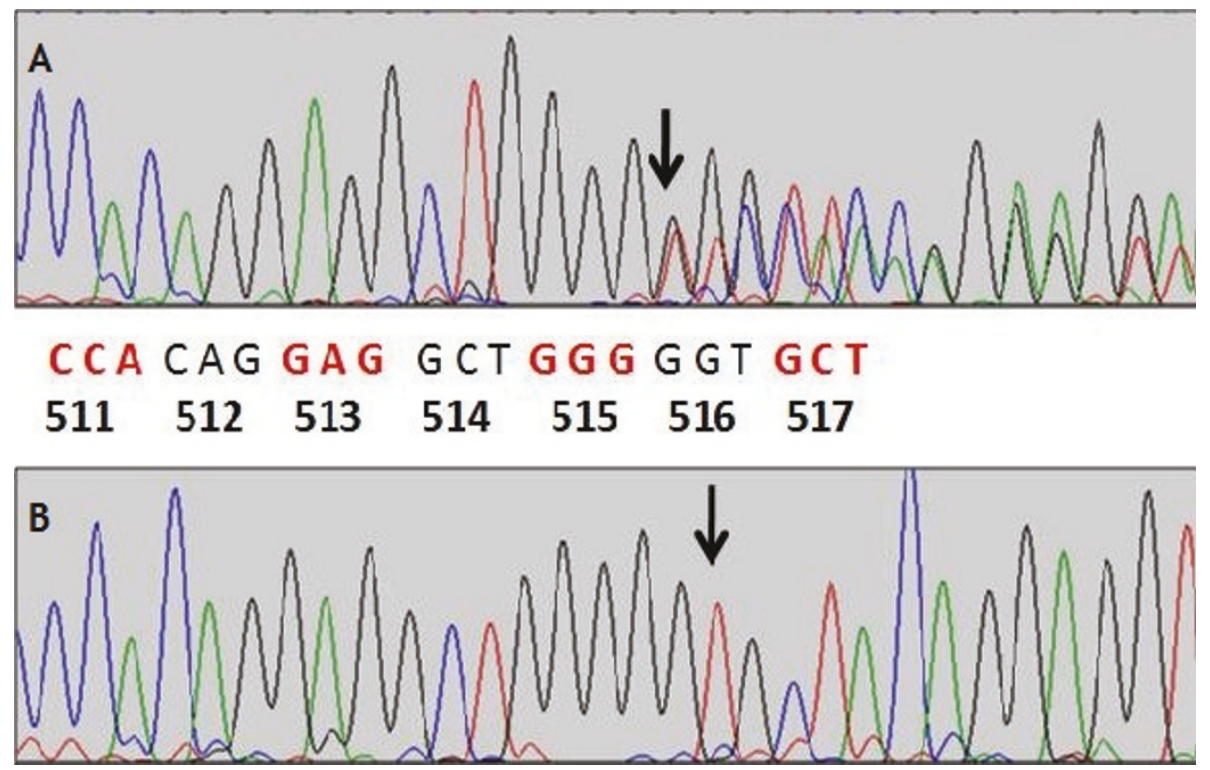

Figure 2 Sequencing of the NIPBL gene. (A) Chromograph from the affected individual showing a heterozygous deletion of a thymidine (-T) at codon 516 (black arrow). (B) Chromograph from a healthy individual with a wild-type sequence. Letters between both chromographs indicate the partial CDNA sequence of the NIPBL gene with corresponding codons beginning with codon 511 .

features in establishing a diagnosis [4]. In patients with a mild clinical presentation, the characteristic facial appearance may not develop until two to three years of age, while it is always present at birth in the severe form [18]. Structural malformations primarily affect the ulnar aspects of the upper limbs and can range from severe reduction defects, with almost complete absence of the forearms, to small hands with fifth-finger clinodactyly and proximally placed thumbs. Developmental delays and mental retardation are generally moderate to severe. With the aid of molecular analyses, it has recently been recognized that many patients with mild CdLS display primarily mental retardation without substantial structural differences [18].

Numerous studies have indicated that mutations in NIPBL cause both mild and severe forms of CdLS [1,2]. These mutations may cause loss-of-function alleles, and the severity of the syndrome generally correlates with the type of mutation [1]. More severe mutations of the $N I P B L$ gene, including deletions, cause more severe disease phenotypes than missense mutations [1]. In contrast, mutations in the SMC3 and SMC1A genes occur in patients with a mild CdLS clinical presentation, including mild facial structural anomalies, no absence or reduction of limbs or digits, no other major structural anomalies or, in some instances, mild to moderate mental retardation with a non-syndromic phenotype [9].

Here, we describe the first molecular genetics diagnosis of an Iranian patient with classic (severe) CdLS. Our patient exhibited characteristic clinical signs of severe
CdLS (distinctive facial appearance, limb reduction, microcephaly, short neck and hirsutism). The severity of CdLS in our patient correlates with previous genetic observations in other patients and supports the NIPBL mutation described here as the disease-causing mutation in our patient. The single-nucleotide deletion (c.516delT) in exon 10 described here is, according to information available in the Human Genome Mutation Database [19] and, to the best of our knowledge, a novel heterozygous mutation in the NIPBL gene. Since both parents of our patient lack this mutation, it strongly suggests that this mutation arose de novo in our patient. Studies including more patients with CdLS in Iran are required to assess the prevalence of this and other NIPBL mutations in the Iranian population and their importance for CdLS pathogenesis.

\section{Consent}

Written informed consent was obtained from the patient's next-of-kin for publication of this case report and any accompanying images. A copy of the written consent is available for review by the Editor-in-Chief of this journal.

\section{Acknowledgements}

We thank the Iranian family of the two-month-old boy for consenting to participate in this study and Mr Baha Salehi for valuable technical assistance.

\section{Author details}

${ }^{1}$ Genetics Department, Shahid Chamran University, Ahwaz, Iran.

${ }^{2}$ Biochemistry Department, Payamenoor University, Tehran, Iran. ${ }^{3}$ Genetic 
Center, Welfare Organization, Khuzestan, Ahwaz, Iran. ${ }^{4}$ Research Center for Hemoglobinopathies and Thalassemia, Ahwaz, Iran.

\section{Authors' contributions}

HG designed the molecular genetic studies and drafted the manuscript. RM carried out the molecular genetic studies and participated in writing the manuscript. GM made the diagnosis. HZ participated in diagnosis and manuscript editing. MP supervised the study. All authors read and approved the final manuscript.

\section{Competing interests}

The authors declare that they have no competing interests.

Received: 8 February 2010 Accepted: 27 June 2011 Published: 27 June 2011

\section{References}

1. Gillis LA, McCallum J, Kaur M, DeScipio C, Yaeger D, Mariani A, Kline AD, Li HH, Devoto M, Jackson LG, Krantz ID: NIPBL mutational analysis in 120 individuals with Cornelia de Lange syndrome and evaluation of genotype-phenotype correlations. Am J Hum Genet 2004, 75:610-623.

2. Krantz ID, McCallum J, Descipio C, Kaur M, Gillis LA, Yaeger D, Jukofsky L, Wasserman N, Bottani A, Morris CA, Nowaczyk MJ, Toriello H, Bamshad MJ, Carey JC, Rappaport E, Kawauchi S, Lander AD, Calof AL, Li HH, Devoto M, Jackson LG: Cornelia de Lange syndrome is caused by mutations in NIPBL, the human homolog of Drosophila melanogaster Nipped-B. Nat Genet 2004, 36:631-635.

3. Barisic I, Tokic V, Loane M, Bianchi F, Calzolari E, Garne E, Wellesley D, Dolk H, EUROCAT Working Group: Descriptive epidemiology of Cornelia de Lange syndrome in Europe. Am J Med Genet A 2008, 146A:51-59.

4. Jackson $\mathrm{L}$, Kline $\mathrm{AD}$, Barr MA, Koch $\mathrm{S}$ : de Lange syndrome: a clinical review of 310 individuals. Am J Med Genet 1993, 47:940-946.

5. Russell KL, Ming JE, Patel K, Jukofsky L, Magnusson M, Krantz ID: Dominant paternal transmission of Cornelia de Lange syndrome: a new case and review of 25 previously reported familial recurrences. Am J Med Genet 2001, 104:267-276

6. Tonkin ET, Wang TJ, Lisgo S, Bamshad MJ, Strachan T: NIPBL, encoding a homolog of fungal Scc2-type sister chromatid cohesion proteins and fly Nipped-B, is mutated in Cornelia de Lange syndrome. Nat Genet 2004, 36:636-641.

7. Jahnke $P, X u$ W, Wülling M, Albrecht $M$, Gabriel H, Gillessen-Kaesbach G, Kaiser FJ: The Cohesin loading factor NIPBL recruits histone deacetylases to mediate local chromatin modifications. Nucleic Acids Res 2008, 36:6450-6458.

8. Musio A, Selicorni A, Focarelli ML, Gervasini C, Milani D, Russo S, Vezzoni P, Larizza L: X-linked Cornelia de Lange syndrome owing to SMC1L1 mutations. Nat Genet 2006, 38:528-530.

9. Deardorff MA, Kaur M, Yaeger D, Rampuria A, Korolev S, Pie J, GilRodríguez C, Arnedo M, Loeys B, Kline AD, Wilson M, Lillquist K, Siu V, Ramos FJ, Musio A, Jackson LS, Dorsett D, Krantz ID: Mutations in cohesin complex members SMC3 and SMC1A cause a mild variant of Cornelia de Lange syndrome with predominant mental retardation. Am J Hum Genet 2007, 80:485-494.

10. Losada A: Cohesin regulation: fashionable ways to wear a ring Chromosoma 2007, 116:321-329.

11. Vrouwe MG, Elghalbzouri-Maghrani E, Meijers M, Schouten P, Godthelp BC, Bhuiyan ZA, Redeker EJ, Mannens MM, Mullenders LH, Pastink A, Darroudi F: Increased DNA damage sensitivity of Cornelia de Lange syndrome cells: evidence for impaired recombinational repair. Hum Mol Genet 2007, 16:1478-1487.

12. Dorsett D, Eissenberg JC, Misulovin Z, Martens A, Redding B, McKim K: Effects of sister chromatid cohesion proteins on cut gene expression during wing development in Drosophila. Development 2005, 132:4743-4753.

13. Dorsett D: Adherin: key to the cohesion ring and Cornelia de Lange syndrome. Curr Biol 2004, 14:834-836.

14. Horsfield JA, Anagnostou SH, Hu JK, Cho KH, Geisler R, Lieschke G, Crosier KE, Crosier PS: Cohesin dependent regulation of Runx genes. Development 2007, 134:2639-2649.

15. Dorsetta D, Krantz ID: On the molecular etiology of Cornelia de Lange syndrome. Ann N Y Acad Sci 2009, 1151:22-37.
16. Hirano T: At the heart of the chromosome: SMC proteins in action. Nat Rev Mol Cell Biol 2006, 7:311-322.

17. Uzun H, Senses DA, Uluba M, Kocabay K: A newborn with Cornelia de Lange syndrome: a case report. Cases J 2008, 1:329.

18. Allanson JE, Hennekam RC, Ireland M: De Lange syndrome: subjective and objective comparison of the classical and mild phenotypes. J Med Genet 1997, 34:645-650.

19. Human Genome Mutation Database. [http://www.hgmd.cf.ac.uk].

doi:10.1186/1752-1947-5-242

Cite this article as: Galehdari et al: Identification of a novel de novo mutation in the NIPBL gene in an Iranian patient with Cornelia de Lange syndrome: A case report. Journal of Medical Case Reports 2011 5:242.

\section{Submit your next manuscript to BioMed Central and take full advantage of:}

- Convenient online submission

- Thorough peer review

- No space constraints or color figure charges

- Immediate publication on acceptance

- Inclusion in PubMed, CAS, Scopus and Google Scholar

- Research which is freely available for redistribution

Submit your manuscript at www.biomedcentral.com/submit
Biomed Central 